\title{
Capecitabine in combination with irinotecan (XELIRI), administered as a 2-weekly schedule, as first-line chemotherapy for patients with metastatic colorectal cancer: a phase II study of the Spanish GOTI group
}

\author{
P Garcia-Alfonso*,I, A Muñoz-Martin', M Mendez-Ureña'2, R Quiben-Pereira², E Gonzalez-Flores ${ }^{3}$ \\ and G Perez-Manga'
}

'Medical Oncology Service, Hospital General Universitario Gregorio Marañón, Doctor Esquerdo 46, Madrid 28007, Spain; ${ }^{2}$ Medical Oncology Service, Hospital Universitario de Móstoles, Río Júcar s/n, Móstoles, Madrid 28935, Spain; ${ }^{3}$ Medical Oncology Senvice, Hospital Universitario Virgen de las Nieves, Avda. Fuerzas Armadas 2, Granada 18014, Spain

\begin{abstract}
BACKGROUND: Combination chemotherapy is standard treatment for metastatic colorectal cancer (MCRC). The aim of this study was to determine the efficacy and safety of capecitabine + irinotecan (2-weekly schedule), as first-line therapy of MCRC.

METHODS: Patients received irinotecan $175 \mathrm{mg} \mathrm{m}^{-2}$ on day I and oral capecitabine $1000 \mathrm{mg} \mathrm{m}^{-2}$ twice daily on days $2-8$ every 2 weeks. For patients aged $\geqslant 65$ years, the starting doses of irinotecan and capecitabine were reduced to 140 and $750 \mathrm{mg} \mathrm{m} \mathrm{m}^{-2}$, respectively.

RESULTS: A total of 53 patients were enrolled: 29 (55\%) were $\geqslant 65$ years old. In an intention-to-treat analysis, complete response was achieved in three patients for an overall response rate (ORR) of 32\%. The disease control rate (ORR + stable disease) was $66 \%$ and the median duration of response was 7.3 months. Median time to progression and overall survival were 9.0 and 19.2 months, respectively. Grade 4 neutropenia was reported in one patient: no other grade 4 toxicities were recorded. Grade 3 diarrhoea occurred in 8 (15\%) patients and grade I-2 hand-foot syndrome in 7 (13\%) patients.

CONCLUSION: Capecitabine and irinotecan, given every 2 weeks, as first-line treatment of MCRC is an active regimen with a manageable toxicity profile, even in older patients.

British Journal of Cancer (2009) I 0 I, 1039- 1043. doi: I0.1038/sj.bjc.660526 I www.bjcancer.com
\end{abstract}

Published online 8 September 2009

(c) 2009 Cancer Research UK

Keywords: capecitabine; colorectal cancer; combined modality therapy; irinotecan

The addition of irinotecan to infusional (FOLFIRI: every 2 weeks) or bolus (IFL: weekly) 5-fluorouracil/leucovorin (5-FU/LV) has been shown to significantly improve progression-free survival, overall survival (OS), and response rate compared with the equivalent 5-FU/LV regimens alone in the first-line treatment of metastatic colorectal cancer (MCRC) (Douillard et al, 2000; Saltz et al, 2000). However, FOLFIRI appears to be better tolerated than IFL and is associated with a lower frequency of toxicities such as diarrhoea, myelosuppression, and sepsis (Benson and Goldberg, 2003; Alimonti et al, 2004; Hwang, 2004).

Several studies show that patients have a strong preference for oral, rather than intravenous, chemotherapy (Liu et al, 1997; Borner et al, 2002; Twelves et al, 2006): the main reasons for this

*Correspondence: Dr P García-Alfonso, Medical Oncology Service, Hospital General Universitario Gregorio Marañón, C/ Doctor Esquerdo, 46, Madrid 28007, Spain; E-mail: pgarcaalfonso@gmail.com

Presented in part at the American Society of Clinical Oncology Gastrointestinal Cancers Symposium, Orlando, Florida, 25-27 January 2008

Received 28 April 2009; revised 17 July 2009; accepted 23 July 2009; published online 8 September 2009 include convenience, problems with intravenous lines (pain, thrombosis or infection; Mueller et al, 1992), and the opportunity to control the environment in which chemotherapy is received. Capecitabine, an inactive oral prodrug, which is preferentially converted to 5-FU in tumour tissue (Meropol, 1998), has emerged as an attractive oral alternative to intravenous 5-FU. Twice-daily oral administration of capecitabine results in continuous exposure to 5-FU, thus avoiding the need for central venous access.

Capecitabine has shown, in large-scale randomised studies in patients with MCRC, a significantly superior response rate and at least equivalent OS compared with bolus 5-FU/LV (Hoff et al, 2001; Van Cutsem et al, 2001). Moreover, capecitabine showed a superior safety profile with significantly less cases of neutropenia, alopecia, diarrhoea, and stomatitis, but more cases of hand-foot syndrome (Cassidy et al, 2002). Following these results, several investigators tested the combination of irinotecan with capecitabine in an attempt to improve on the available 5-FU/LV-based regimens. Encouraging efficacy results from phase II studies were reported with combination regimens of capecitabine and irinotecan given weekly, on days 1 and 8 (CAPIRI) or 3-weekly (XELIRI) as first-line treatment for MCRC (Bajetta et al, 2004; Park et al, 2004; Borner et al, 2005; Cartwright et al, 2005; Kim et al, 2005; 
Rea et al, 2005; Patt et al, 2007). However, dose reductions of both drugs were necessary in most studies to improve the safety profile of these regimens. The 3-weekly XELIRI regimen was selected for further testing in phase III studies. Although the large CAIRO study (Koopman et al, 2007) showed that, with careful dose management, the XELIRI regimen was effective and had an acceptable tolerability profile, XELIRI was associated with unacceptable toxicity in two other phase III trials (Fuchs et al, 2007; Kohne et al, 2008). These data suggest that the optimal doses and schedule for the capecitabine-irinotecan combination have yet to be identified.

The objective of this phase II study was to evaluate the feasibility of a new 2-weekly schedule of capecitabine and irinotecan (similar to the FOLFIRI scheme) in an attempt to improve the tolerability of this combination as first-line therapy in patients with MCRC.

\section{MATERIALS AND METHODS}

Local ethics committee approval was obtained before enrolment of any patient into this multicentre, national, open-label, phase II trial. It was conducted in accordance with the Declaration of Helsinki Principles and its subsequent amendments, as well as Good Clinical Practice Guidelines. Signed informed consent was obtained from all patients before study entry.

The primary study objective was to determine the overall response rate (ORR) to the 2-weekly capecitabine-irinotecan regimen. Secondary objectives included duration of response, time to progression (TTP), OS, and tolerability.

\section{Eligibility criteria}

Patients with histologically confirmed locally advanced colorectal cancer or MCRC, which was measurable according to the RECIST criteria (Therasse et al, 2000), were eligible. Patients were either chemotherapy-naive or were to have undergone adjuvant chemotherapy $\geqslant 6$ months before study entry. Other eligibility criteria included: age 18-75 years; Eastern Cooperative Oncology Group (ECOG) performance status $\leqslant 2$; life expectancy of more than 3 months; adequate haematological, liver, and renal function (i.e., haemoglobin $\geqslant 10 \mathrm{~g} \mathrm{dl}^{-1}$, absolute neutrophil count of $\geqslant 1.5 \times$ $10^{9} 1^{-1}$, and platelets $\geqslant 100 \times 10^{9} 1^{-1}$; total bilirubin $\leqslant 1.25 \times$ the upper limit of normal (ULN), serum transaminase and alkaline phosphatase levels of $\leqslant 2.5 \times$ ULN (total bilirubin $\leqslant 1.5 \times \mathrm{ULN}$, serum transaminase and alkaline phosphatase levels $\leqslant 5 \times \mathrm{ULN}$, in case of liver metastases); creatinine $\leqslant 1.5 \times \mathrm{ULN}$ ); absence of any primary tumour other than non-melanoma skin cancer or in situ cervical carcinoma. Patients with central nervous system metastasis, unresolved bowel obstruction or subobstruction, inflammatory enteropathy, malabsorption syndrome, any uncontrolled chronic disease, or organ allografts were excluded.

\section{Treatment schedule}

On the basis of our previous phase I study (Garcia-Alfonso et al, 2003), patients received irinotecan $175 \mathrm{mg} \mathrm{m}^{-2}$ as a $30-\mathrm{min}$ intravenous infusion on day 1 , followed by oral capecitabine $1000 \mathrm{mg} \mathrm{m}^{-2}$ twice daily on days $2-8$, every 2 weeks. Taking into consideration the irinotecan package insert suggestions (i.e., caution in patients $\geqslant 65$ years and a lower dose in patients $\geqslant 70$ years), the starting doses of both irinotecan and capecitabine were reduced to 140 and $750 \mathrm{mg} \mathrm{m}^{-2}$ twice daily, respectively, in patients $\geqslant 65$ years of age. The study treatment was continued until disease progression, severe toxicity, treatment refusal (unrelated to toxicity), investigator decision, or death.

Both drugs were administered according to the guidelines used for irinotecan monotherapy, including recommendations for the use of concurrent antiemetics, atropine, and loperamide.
Appropriate dose interruptions/reductions for capecitabine and/or irinotecan were implemented in the event of specific toxicities, depending on their nature and intensity.

Patients were assessed for toxicity before each infusion using the National Cancer Institute-Common Toxicity Criteria (NCI-CTC, version 2.0) of April 1999.

\section{Evaluations during the study}

Physical examination and laboratory studies, including complete blood counts, serum liver function tests, calcium, ions, and creatinine levels, were performed within 7 days of enrolment. Electrocardiography was carried out and carcinoembryonic antigen levels were determined within 21 days before starting of the treatment. A chest radiograph or computed tomography (CT) scan, and abdominal CT scan were completed within 4 weeks of enrolment. During treatment, safety assessments, biochemical analysis, and blood counts were performed before each cycle (every 2 weeks).

Evaluation of disease status, according to the RECIST criteria (Therasse et al, 2000), was carried out every three cycles (6 weeks) during treatment, and every 8 weeks subsequently until disease progression, death, or loss to follow-up.

The duration of response was measured from the first documentation of response to disease progression (PD). TTP was calculated as the time from inclusion in the study until the first report of PD. Patients with no evidence of PD at the time of their last visit were censored at that time. OS was measured from the time of inclusion to date of death.

\section{Statistical considerations}

Sample size was calculated using the optimal method described by Simon (1989). We assumed a minimum efficacy (p0) of $20 \%$ and an optimal $40 \%$ response rate with the study combination (p1) (similar to the $35-39 \%$ obtained with the combination of irinotecan and 5-FU/LV in two pivotal trials; Douillard et al, 2000; Saltz et al, 2000), with $\alpha$ - and $\beta$-error probabilities of 0.05 and 0.1 , respectively. With these considerations, if $\geqslant 16$ of a total of 54 patients responded to treatment, further phase III or other trials would be warranted.

All efficacy and safety analyses were carried out on the intention-to-treat (ITT) population, which included all recruited patients. The probabilities of time-to-event parameters were estimated using the Kaplan-Meier method with $95 \%$ confidence intervals (95\% CIs).

\section{RESULTS}

Between June 2002 and January 2005, a total of 53 patients from three Spanish centres were enrolled into the study. The baseline characteristics of the patients are summarised in Table 1. Of these, $47(89 \%)$ patients had an ECOG performance status of $<2$ at baseline, 29 (55\%) were at least 65 years old, and $57 \%$ had at least two organs involved (median 2 and maximum 8 ), with the liver being the most common site of metastatic disease.

\section{Treatment compliance}

A total of 489 cycles were administered with a median of 11 (range 2-12) cycles per patient. Irinotecan doses were delayed in 56 cycles $(12 \%)$, and dose reductions were required in 33 cycles (7\%). Globally, 3423 doses of capecitabine were administered: of those, 106 administrations (3.1\%) were delayed, and dose reductions were required in 171 cases (5\%). No significant differences in drug administrations were observed between patients aged $>65$ and $\leqslant 65$ years. 
Two-weekly capecitabine-irinotecan in colorectal cancer

Table I Patient characteristics $(n=53)$

\begin{tabular}{|c|c|c|}
\hline Parameter & No. of patients & $\%$ \\
\hline \multicolumn{3}{|l|}{ Sex } \\
\hline Male & 39 & 74 \\
\hline Female & 14 & 26 \\
\hline \multicolumn{3}{|l|}{ Age, years } \\
\hline Median & 66 & \\
\hline Range & $42-80$ & \\
\hline \multicolumn{3}{|l|}{ ECOG performance status } \\
\hline 0 & 17 & 32 \\
\hline I & 30 & 57 \\
\hline 2 & 3 & 6 \\
\hline Non-specified & 3 & 6 \\
\hline \multicolumn{3}{|l|}{ Primary site } \\
\hline Colon & 30 & 57 \\
\hline Rectum & 22 & 41 \\
\hline Both & I & 2 \\
\hline \multicolumn{3}{|l|}{ Metastatic site } \\
\hline Liver & 31 & 61 \\
\hline Lung & 13 & 26 \\
\hline Peritoneum & 8 & 16 \\
\hline Other & 15 & 29 \\
\hline \multicolumn{3}{|l|}{ Prior therapy } \\
\hline Radiotherapy & 10 & 19 \\
\hline Surgery & 41 & 77 \\
\hline Adjuvant chemotherapy & 22 & 42 \\
\hline
\end{tabular}

Abbreviation: $\mathrm{ECOG}=$ Eastern Cooperative Oncology Group.

\section{Toxicity}

All patients were evaluable for toxicity. The main haematological and non-haematological toxicities by patient are summarised in Table 2. Grade 4 neutropenia was reported in one patient; no other grade 4 toxicities were recorded. The most frequent nonhaematological toxicities were gastrointestinal events (i.e. nausea, vomiting, and diarrhoea), as well as alopecia and asthenia; in most cases, these toxicities did not reach grade $>2$. In particular, grade 3 diarrhoea was uncommon (eight patients, 11 cycles), and grade 1-2 hand-foot syndrome was observed in seven patients (no grade $>2$ hand-foot syndrome was reported).

No significant differences related to toxicity were observed in patients aged $\geqslant 65$ years and those $<65$ years, although there was a tendency for a later recovery in older patients (data not shown).

There were no treatment-related deaths during the study or within 28 days after the last study dose.

\section{Efficacy assessment}

In an ITT analysis, in which all 53 patients were considered, $3(6 \%)$ patients attained a complete response and 14 patients a partial response, for an ORR of 32\% (95\% CI: $20-46 \%$ ). In addition, 18 (34\%) patients had stable disease, providing a disease control rate (ORR + stable disease) of $66 \%$ (95\% CI: $52-79 \%)$. The median duration of response was 7.3 (95\% CI: $6.2-8.8$ ) months.

The median TTP and OS were 9.0 (95\% CI: $5.7-10.4)$ and 19.2 (95\% CI: 14.1-23.3) months, respectively.

\section{DISCUSSION}

Combination chemotherapy is standard treatment for MCRC, often combined with a biological agent. Until recently oxaliplatin regimens have probably been the most used as first line treatment
Table 2 Maximum toxicity per patient according to the $\mathrm{NCl}-\mathrm{CTC}$ grade $(n=53)$

\begin{tabular}{|c|c|c|c|c|}
\hline & \multicolumn{2}{|c|}{ All grades } & \multicolumn{2}{|c|}{ Grade 3} \\
\hline & $n$ & $\%$ & $n$ & $\%$ \\
\hline \multicolumn{5}{|l|}{ Haematological events } \\
\hline Anaemia & 23 & 43 & - & - \\
\hline Leucopenia & 4 & 8 & - & - \\
\hline Neutropenia & 12 & 23 & 3 & 6 \\
\hline Thrombopenia & 3 & 6 & 1 & 2 \\
\hline \multicolumn{5}{|l|}{ Non-haematological events } \\
\hline Fever & 8 & 15 & - & - \\
\hline Alopecia & 14 & 26 & 2 & 4 \\
\hline Nausea & 30 & 57 & 4 & 8 \\
\hline Vomiting & 24 & 45 & 2 & 4 \\
\hline Diarrhoea & 27 & 51 & 8 & 15 \\
\hline Epigastralgia & 8 & 15 & 1 & 2 \\
\hline Asthenia & 30 & 57 & 7 & 13 \\
\hline Headache & 3 & 6 & - & - \\
\hline Hand-foot syndrome & 7 & 13 & - & - \\
\hline Mucositis & $\mid 1$ & 21 & - & - \\
\hline Liver & 2 & 4 & - & - \\
\hline Renal & 2 & 4 & I & 2 \\
\hline Skin & 3 & 6 & - & - \\
\hline Anorexia & $1 \mid$ & 21 & I & 2 \\
\hline
\end{tabular}

Abbreviation: $\mathrm{NCl}-\mathrm{CTC}=$ National Cancer Institute-Common Toxicity Criteria.

of MCRC, but as oxaliplatin adjuvant therapy is now usually selected, irinotecan combinations are more likely to be used at first progression. Combining irinotecan with capecitabine will make a regimen that is better tolerated and preferred by patients.

This phase II study shows that a novel 2-weekly schedule of capecitabine plus irinotecan as first-line treatment for MCRC is feasible, with notable efficacy and safety, even in older patients. To date, we are not aware of the publication of any other phase II prospective study of capecitabine plus irinotecan using this schedule. The choice of this regimen was based on our previous phase I study (Garcia-Alfonso et al, 2003), which aimed to simulate the FOLFIRI scheme, thereby replacing 5-FU/LV with oral capecitabine.

Previous phase II trial results suggested that the 3-weekly XELIRI regimen was less toxic than those involving irinotecan given on days 1 and 8 (CAPIRI) or on a weekly basis (Bajetta et al, 2004; Borner et al, 2005), but the initial doses used with 3-weekly XELIRI in those trials had to be reduced in a considerable number of patients. Moreover, XELIRI showed better efficacy than the weekly regimen (Borner et al, 2005), probably because of the higher dose intensity of irinotecan in the XELIRI arm. Thus, the 3-weekly XELIRI regimen was taken forward for phase III testing. Although XELIRI was found to be effective with a manageable toxicity profile in the large CAIRO trial (Koopman et al, 2007), unacceptable rates of toxicity were reported in both the EORTC 40015 (Kohne et al, 2008) and BICC-C (Fuchs et al, 2007) studies, both of which compared XELIRI with 5-FU-based irinotecan combinations with a second randomisation to placebo or celecoxib. These findings suggested that the optimal capecitabine-irinotecan schedule had not yet been identified.

Although a comparison of results from different phase II studies can be only speculative, the efficacy of our schedule is in line with that obtained by the other groups who have also published response data in phase II trials testing capecitabine-irinotecan combination regimens (Bajetta et al, 2004; Park et al, 2004; Borner et al, 2005; Cartwright et al, 2005; Kim et al, 2005; Rea et al, 2005; Patt et al, 2007; Choi et al, 2008) (Table 3). Indeed, our median TTP and OS are among the highest of those published to date with this combination. Moreover, the time-to-event results in this study 
Table 3 Phase II studies of capecitabine + irinotecan as first-line treatment of metastatic colorectal cancer

\begin{tabular}{|c|c|c|c|c|c|c|}
\hline Schedule & $\mathbf{N}$ & RR (\%) & Median TTP (months) & Median OS (months) & Neutropenia & Diarrhoea \\
\hline XELIRI (Bajetta et al, 2004) & 140 & $47^{\mathrm{a}}$ & $8.3^{b}$ & - & 5 & 36 \\
\hline CAPIRI & & $44^{\mathrm{a}}$ & $7.6^{b}$ & & & 17 \\
\hline XELIRI weekly (Borner et al, 2005) & 75 & 34 & 6.9 & 17.4 & 5 & 34 \\
\hline XELIRI & & 35 & 9.2 & 24.7 & 19 & 19 \\
\hline XELIRI Park et al, 2004) & 39 & 44 & 6.7 & - & 10 & 10 \\
\hline XELIRI (Patt et al, 2007) & 52 & 50 & 7.8 & 16.8 & 25 & 20 \\
\hline XELIRI (Rea et al, 2005) & 57 & 42 & 8.3 & - & 28 & 19 \\
\hline XELIRI (Cartwright et al, 2005) & 49 & $45^{\mathrm{a}}$ & $6.2^{b}$ & 13.4 & 12 & 20 \\
\hline CAPIRI (Kim et al, 2005) & 47 & 49 & 7.5 & 19.5 & || & 24 \\
\hline XELIRI 2-weekly (Choi et al, 2008) & 43 & 51 & 10.0 & 15.0 & 5 & 8 \\
\hline XELIRI 2-weekly (this study) & 53 & 32 & 9.0 & 19.2 & 6 & 15 \\
\hline
\end{tabular}

Abbreviations: CAPIRI = capecitabine on days $2-15+$ irinotecan on days I and $8 ; \mathrm{OS}=$ overall survival; RR = response rate; TTP = time to progression; $X E L I R I=$ capecitabine

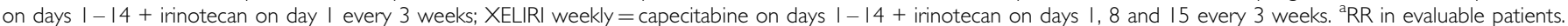
brogression-free survival.

compare favourably with those reported from recent phase III trials of the FOLFIRI regimen (Tournigand et al, 2004; Van Cutsem et al, 2007): median TTP (9.0 vs progression-free survival of 8.0 and 8.5 months) and median OS (19.2 vs 21.5 months).

It is noteworthy that the regimen tested in this study shows good tolerability (dose reductions were required in only $7 \%$ of cycles), with predominantly mild or moderate adverse events only. Importantly, there were no treatment-related deaths during our study. No grade 4 non-haematological toxicities were reported and only one case $(3 \%)$ of non-complicated grade 4 neutropenia was documented. As expected with this combination, diarrhoea was the main adverse event, but with a low rate of grade 3 events $(15 \%$ of patients) and no grade 4 events. Hand-foot syndrome, a welldocumented capecitabine-associated event, was only reported in seven patients and all cases were grade 1 or 2 . In Table 3 , which summarises the main grade 3-4 toxicities per patient reported in previous phase II studies testing the combination of capecitabine and irinotecan, the improved tolerability of the 2-weekly regimen is notable: grade 3-4 neutropenia and diarrhoea ranged between $5-28$ and $8-34 \%$ in other phase II studies, respectively, compared with respective rates of 6 and 15\% in this study. Unlike the current study, grade 3-4 hand-foot syndrome was reported in most of those studies (Cartwright et al, 2005; Patt et al, 2007; Choi et al, 2008). Our regimen also appears to be associated with a lower rate of grade 3-4 neutropenia (6 vs 24-23\%) and a similar rate of grade 3-4 diarrhoea (15 vs 14-11\%) compared with FOLFIRI (Tournigand et al, 2004; Van Cutsem et al, 2007).

Implementation of up-front dose reductions in older patients also appears to have contributed to a better tolerability profile than has been previously reported for other capecitabine-irinotecan regimens. This approach has also been used successfully with the XELIRI regimen in patients with other known risk factors, for example, renal impairment, previous pelvic irradiation, and older age (Patt et al, 2007; Van Cutsem et al, 2007).

In conclusion, 2-weekly administration of irinotecan in combination with capecitabine is effective and safe as first-line chemotherapy for advanced colorectal cancer or MCRC and may be suitable for use with targeted agents, such as cetuximab or bevacizumab. Therefore, phase III studies of this regimen are warranted.

\section{REFERENCES}

Alimonti A, Gelibter A, Pavese I, Satta F, Cognetti F, Ferretti G, Rasio D, Vecchione A, Di PM (2004) New approaches to prevent intestinal toxicity of irinotecan-based regimens. Cancer Treat Rev 30: 555-562

Bajetta E, Di BM, Mariani L, Cassata A, Artale S, Frustaci S, Pinotti G, Bonetti A, Carreca I, Biasco G, Bonaglia L, Marini G, Iannelli A, Cortinovis D, Ferrario E, Beretta E, Lambiase A, Buzzoni R (2004) Randomized multicenter Phase II trial of two different schedules of irinotecan combined with capecitabine as first-line treatment in metastatic colorectal carcinoma. Cancer 100: 279-287

Benson III AB, Goldberg RM (2003) Optimal use of the combination of irinotecan and 5-fluorouracil. Semin Oncol 30: 68-77

Borner MM, Bernhard J, Dietrich D, Popescu R, Wernli M, Saletti P, Rauch D, Herrmann R, Koeberle D, Honegger H, Brauchli P, Lanz D, Roth AD (2005) A randomized phase II trial of capecitabine and two different schedules of irinotecan in first-line treatment of metastatic colorectal cancer: efficacy, quality-of-life and toxicity. Ann Oncol 16: 282-288

Borner MM, Schoffski P, de WR, Caponigro F, Comella G, Sulkes A, Greim G, Peters GJ, van der BK, Wanders J, de Boer RF, Martin C, Fumoleau P (2002) Patient preference and pharmacokinetics of oral modulated UFT $v s$ intravenous fluorouracil and leucovorin: a randomised crossover trial in advanced colorectal cancer. Eur J Cancer 38: 349-358

Cartwright T, Lopez T, Vukelja SJ, Encarnacion C, Boehm KA, Asmar L (2005) Results of a phase II open-label study of capecitabine in combination with irinotecan as first-line treatment for metastatic colorectal cancer. Clin Colorectal Cancer 5: 50-56
Cassidy J, Twelves C, Van CE, Hoff P, Bajetta E, Boyer M, Bugat R, Burger U, Garin A, Graeven U, McKendric J, Maroun J, Marshall J, Osterwalder B, Perez-Manga G, Rosso R, Rougier P, Schilsky RL (2002) First-line oral capecitabine therapy in metastatic colorectal cancer: a favorable safety profile compared with intravenous 5-fluorouracil/leucovorin. Ann Oncol 13: $566-575$

Choi CK, Chan RT, Tung SY, Lui L, Siu S, Au GK, Ho JW, Law WL (2008) Efficacy of combination chemotherapy with irinotecan (CPT-11) plus capecitabine in patients with metastatic or advanced colorectal carcinoma - a dual-centre phase II study: the MAC-6. Clin Oncol (R Coll Radiol) 20: $168-175$

Douillard JY, Cunningham D, Roth AD, Navarro M, James RD, Karasek P, Jandik P, Iveson T, Carmichael J, Alakl M, Gruia G, Awad L, Rougier P (2000) Irinotecan combined with fluorouracil compared with fluorouracil alone as first-line treatment for metastatic colorectal cancer: a multicentre randomised trial. Lancet 355: 1041-1047

Fuchs CS, Marshall J, Mitchell E, Wierzbicki R, Ganju V, Jeffery M, Schulz J, Richards D, Soufi-Mahjoubi R, Wang B, Barrueco J (2007) Randomized, controlled trial of irinotecan plus infusional, bolus, or oral fluoropyrimidines in first-line treatment of metastatic colorectal cancer: results from the BICC-C Study. J Clin Oncol 25: 4779-4786

Garcia-Alfonso P, Muñoz A, Mendez M, Garcia-Adrian S, Lopez-Criado P, Alvarez R, Siso I, Perez-Manga G (2003) A phase I study of irinotecan (CPT-11) and capecitabine (XL) as second line treatment in advanced colorectal cancer. Eur J Cancer 1: S73 
Hoff PM, Ansari R, Batist G, Cox J, Kocha W, Kuperminc M, Maroun J, Walde D, Weaver C, Harrison E, Burger HU, Osterwalder B, Wong AO, Wong $\mathrm{R}$ (2001) Comparison of oral capecitabine $v s$ intravenous fluorouracil plus leucovorin as first-line treatment in 605 patients with metastatic colorectal cancer: results of a randomized phase III study. J Clin Oncol 19: 2282-2292

Hwang JJ (2004) Irinotecan and 5-FU/leucovorin in metastatic colorectal cancer: balancing efficacy, toxicity, and logistics. Oncology (Williston Park) 18: $26-34$

Kim TW, Kang WK, Chang HM, Park JO, Ryoo BY, Ahn JS, Zang DY, Lee KH, Kang YK, Kim SR, Kim HK (2005) Multicenter phase II study of oral capecitabine plus irinotecan as first-line chemotherapy in advanced colorectal cancer: a Korean Cancer Study Group trial. Acta Oncol 44: $230-235$

Kohne CH, De Greve J, Hartmann JT, Lang I, Vergauwe P, Becker K, Braumann D, Joosens E, Muller L, Janssens J, Bokemeyer C, Reimer P, Link H, Spath-Schwalbe E, Wilke HJ, Bleiberg H, Van Den Brande J, Debois M, Bethe U, Van Cutsem E (2008) Irinotecan combined with infusional 5-fluorouracil/folinic acid or capecitabine plus celecoxib or placebo in the first-line treatment of patients with metastatic colorectal cancer. EORTC study 40015. Ann Oncol 19: 920-926

Koopman M, Antonini NF, Douma J, Wals J, Honkoop AH, Erdkamp FL, de Jong RS, Rodenburg CJ, Vreugdenhil G, Loosveld OJ, van BA, Sinnige HA, Creemers GJ, Tesselaar ME, Slee PH, Werter MJ, Mol L, Dalesio O, Punt CJ (2007) Sequential vs combination chemotherapy with capecitabine, irinotecan, and oxaliplatin in advanced colorectal cancer (CAIRO): a phase III randomised controlled trial. Lancet 370: $135-142$

Liu G, Franssen E, Fitch MI, Warner E (1997) Patient preferences for oral vs intravenous palliative chemotherapy. J Clin Oncol 15: 110-115

Meropol NJ (1998) Oral fluoropyrimidines in the treatment of colorectal cancer. Eur J Cancer 34: 1509-1513

Mueller BU, Skelton J, Callender DP, Marshall D, Gress J, Longo D, Norton J, Rubin M, Venzon D, Pizzo PA (1992) A prospective randomized trial comparing the infectious and noninfectious complications of an externalized catheter $v s$ a subcutaneously implanted device in cancer patients. J Clin Oncol 10: 1943-1948

Park SH, Bang SM, Cho EK, Baek JH, Oh JH, Im SA, Park YS, Shin DB, Lee JH (2004) First-line chemotherapy with irinotecan plus capecitabine for advanced colorectal cancer. Oncology 66: 353-357

Patt YZ, Lee FC, Liebmann JE, Diamandidis D, Eckhardt SG, Javle M, Justice GR, Keiser W, Salvatore JR, Bexon A, Lin E (2007) Capecitabine plus 3-weekly irinotecan (XELIRI regimen) as first-line chemotherapy for metastatic colorectal cancer: phase II trial results. Am J Clin Oncol 30: $350-357$

Rea DW, Nortier JW, Ten Bokkel Huinink WW, Falk S, Richel DJ, Maughan T, Groenewegen G, Smit JM, Steven N, Bakker JM, Semiond D, Kerr DJ, Punt CJ (2005) A phase I/II and pharmacokinetic study of irinotecan in combination with capecitabine as first-line therapy for advanced colorectal cancer. Ann Oncol 16: 1123-1132

Saltz LB, Cox JV, Blanke C, Rosen LS, Fehrenbacher L, Moore MJ, Maroun JA, Ackland SP, Locker PK, Pirotta N, Elfring GL, Miller LL (2000) Irinotecan plus fluorouracil and leucovorin for metastatic colorectal cancer. Irinotecan Study Group. N Engl J Med 343: $905-914$

Simon R (1989) Optimal two-stage designs for phase II clinical trials. Control Clin Trials 10: 1-10

Therasse P, Arbuck SG, Eisenhauer EA, Wanders J, Kaplan RS, Rubinstein L, Verweij J, Van GM, van Oosterom AT, Christian MC, Gwyther SG (2000) New guidelines to evaluate the response to treatment in solid tumors. European Organization for Research and Treatment of Cancer, National Cancer Institute of the United States, National Cancer Institute of Canada. J Natl Cancer Inst 92: 205-216

Tournigand C, Andre T, Achille E, Lledo G, Flesh M, Mery-Mignard D, Quinaux E, Couteau C, Buyse M, Ganem G, Landi B, Colin P, Louvet C, de GA (2004) FOLFIRI followed by FOLFOX6 or the reverse sequence in advanced colorectal cancer: a randomized GERCOR study. J Clin Oncol 22: $229-237$

Twelves C, Gollins S, Grieve R, Samuel L (2006) A randomised cross-over trial comparing patient preference for oral capecitabine and 5 -fluorouracil/leucovorin regimens in patients with advanced colorectal cancer. Ann Oncol 17: 239-245

Van Cutsem E, Nowacki M, Lang I, Cascinu S, Shchepotin I, Maurel J, Rougier P, Cunningham D, Nippgen J, Köhne C (2007) Randomized phase III study of irinotecan and 5-FU/FA with or without cetuximab in the first-line treatment of patients with metastatic colorectal cancer (mCRC): The CRYSTAL trial. J Clin Oncol 25: 4000

Van Cutsem E, Twelves C, Cassidy J, Allman D, Bajetta E, Boyer M, Bugat R, Findlay M, Frings S, Jahn M, McKendrick J, Osterwalder B, Perez-Manga G, Rosso R, Rougier P, Schmiegel WH, Seitz JF, Thompson P, Vieitez JM, Weitzel C, Harper P (2001) Oral capecitabine compared with intravenous fluorouracil plus leucovorin in patients with metastatic colorectal cancer: results of a large phase III study. J Clin Oncol 19: 4097-4106 